\title{
A equalização e o regime de colaboração: duas experiências de arranjos territoriais colaborativos na área de educação
}

\section{Equalization and the collaborative regime: two experiences of territorial collaborative arrangements in education}

DOI: $10.46814 / \operatorname{lajdv} 3 n 2-030$

Recebimento dos originais: 23/12/2020

Aceitação para publicação: 26/02/2021

\section{Ubirajara Couto Lima}

Professor Assistente da Universidade Estadual do Sudoeste da Bahia e aluno do Programa Doutoral em Ciências da Educação, da Faculdade de Psicologia e Ciências da Educação, Universidade do Porto, Portugal. Orientador: Professor Doutor Tiago Neves

UESB

E-mail: uclima@uesb.edu.br

\section{RESUMO}

Este artigo refere-se a resultado parcial de pesquisa de doutoramento na área de Educação cujo objetivo consiste em identificar e analisar as experiências de Arranjos de Desenvolvimento da Educação (ADE's) no Estado da Bahia, focalizando a relação destas com o regime de colaboração e avaliando a sua contribuição para o desenvolvimento territorial e melhoria da qualidade da educação dos municípios envolvidos. Firmado numa abordagem qualitativa e tendo como estratégia metodológica o estudo de caso, este artigo tenciona apresentar duas experiências de arranjos, caracterizando-as - quanto à sua história, atores participantes, institucionalização, estrutura e modo de funcionamento -, e problematizando a sua articulação com o instituto do regime de colaboração, sobretudo no tocante ao compartilhamento de competências políticas, técnicas e financeiras. As experiências analisadas, no que diz respeito aos conteúdos de colaboração e cooperação, apresentam, em menor ou maior grau, os seguintes aspectos: articulação federativa; capacidade de gestão institucional; modelos de gestão pedagógica; e instrumentos de transparência e controle social e democrático. No entanto, apesar de serem modelos exitosos de organização cooperativa, evidenciou-se a necessidade de ações coordenadoras e indutivas da União e dos estados, que no caso da Bahia, no plano intergovernamental, tem um papel inexpressivo na articulação federativa com os municípios.

Palavras-chave: Equalização. Regime de colaboração. Educação.

\section{INTRODUÇÃO}

No Brasil, quando o assunto são os Arranjos de Desenvolvimento da Educação (ADE’s) e sua relação com o instituto do regime de colaboração, está posto um campo de disputa: de um lado os reformadores empresariais defendendo os ADE's como sinônimo do regime de colaboração e envidando esforços para esvaziar a possibilidade política de sua regulamentação; de outro, os profissionais da educação, a partir de sua atuação em vários órgãos e instâncias, envidando esforços para compreender nosso complexo pacto federativo e empenhando-se em buscar alternativas de financiamento e possibilidade de fóruns interfederativos que possam se institucionalizar e servir de 
base para a lei complementar do regime de colaboração que assegure a oferta de educação em quantidade e qualidade com base no princípio da equalização (ARAÚJO, 2013).

É nesse campo de disputa, de natureza teórica e prática, que se insere a proposta de investigação cujo desafio inicial, e do qual trata este artigo, é identificar as experiências de ADE's no estado da Bahia, analisando de que modo essas experiências se articulam com o instituto do regime de colaboração, nomeadamente sobre o compartilhamento de competências políticas, técnicas e financeiras.

\section{DUAS EXPERIÊNCIAS DE ADE'S NA EDUCAÇÃO: DA EQUALIZAÇÃO AO REGIME DE COLABORAÇÃO}

\subsection{O ARRANJO DE DESENVOLVIMENTO DA CHAPADA DIAMANTINA E SEMIÁRIDO}

A Chapada Diamantina é uma cadeia montanhosa localizada no estado da Bahia, Brasil, e constitui um dos vinte e sete Territórios de Identidade $^{1}$ do referido estado. Segundo a publicação Perfil dos Territórios de Identidade do Estado da Bahia (2015), o Território de Identidade Chapada Diamantina possui população de 371,8 mil pessoas, de acordo com o Censo 2010 do IBGE 2 , e extensão total de 30,4 mil quilômetros quadrados, sendo composto por 24 municípios: Abaíra, Andaraí, Barra da Estiva, Boninal, Bonito, Ibicoara, Ibitiara, Iramaia, Iraquara, Itaetê, Jussiape, Lençóis, Marcionílio Souza, Morro do Chapéu, Mucugê, Nova Redenção, Novo Horizonte, Palmeiras, Piatã, Rio de Contas, Seabra, Souto Soares, Utinga e Wagner. No território, predominam os municípios com população entre 10 mil e 30 mil habitantes. Os dois maiores municípios da Chapada Diamantina são Seabra (41,7 mil) e Morro do Chapéu (35,1 mil).

No âmbito da educação, um dos avanços verificados no Território Chapada Diamantina foi a redução do número de analfabetos entre 2000 e 2010. A taxa caiu de 28,3\% para 20,8\% para a população com idade superior a 15 anos. Note-se, porém, que é superior à média baiana, que alcança 16,3\%. O acesso à educação na faixa etária entre 6 e 14 anos caminha para a universalização no território, tendo passado de $90 \%$ para $97,3 \%$ entre 2000 e 2010. Com relação à faixa etária entre 4 e 5 anos a universalização ainda é um desafio, embora o avanço no mesmo período tenha sido expressivo, passando de 42,9\% para 79,7\%. Com relação à população com idade entre 15 e 17 anos, houve razoável elevação do acesso à educação entre 2000 e 2010: passou de 73,5\% para 83,5\%. O grande desafio, porém, coloca-se em relação à permanência desse segmento em sala de aula: a taxa de escolaridade

\footnotetext{
${ }^{1}$ Os Territórios de Identidade foram implantados em 2007 pela Superintendência de Estudos Econômicos e Sociais da Bahia (SEI), vinculada à Secretaria de Planejamento do Estado da Bahia (SEPLAN). Os Territórios de Identidade foram constituídos a partir da especificidade dos arranjos sociais e locais de cada região. Esta divisão vem sendo utilizada para a implementação de políticas públicas no estado (SEPLAN, 2007).

${ }^{2}$ Instituto Brasileiro de Geografia e Estatística.
} 
líquida, que considera os que efetivamente permanecem na escola, é muito baixa: $12,3 \%$ e 39,3\% em 2000 e 2010, respectivamente (BAHIA, 2015).

É nesse contexto que, no ano de 1997, teve início o Projeto Chapada, constituído por um grupo formado por educadores, profissionais liberais, membros de organizações da sociedade civil e gestores municipais, cuja pergunta inquietadora era: “como uma rede de municípios e educadores pode transformar para sempre a situação educacional em determinada região? ". A região, em questão, apresentava limitações que incluíam a precária formação de professores, a ausência de coordenadores pedagógicos capacitados para levar a cabo as avaliações pertinentes, e os critérios inadequados de seleção dos diretores. Em resposta aos desafios, nasceu a iniciativa que combinava a formação continuada de coordenadores pedagógicos e ações de mobilização social em prol da melhoria da qualidade da educação pública na região da Chapada Diamantina, estado da Bahia (OLIVEIRA; MEIRELLES, 2012, p. 114).

Entre o ano de 1997 e 1998, com o apoio do "Programa Ver para Crer" (criado em 1995), vinculado ao Instituto Natura ${ }^{3}$, a Associação de Pais e Alunos do Colégio Estadual de Primeiro Grau de Caeté-Açu (distrito rural do município de Palmeiras, Bahia) realizou um Programa de Desenvolvimento e Auxílio ao Professor, voltado para a formação de professores do Ensino Fundamental, e com foco em referenciais teóricos construtivistas, além de recursos e instrumentos para auxiliar a prática pedagógica.

Os resultados da aludida ação foram muito expressivos, refletindo uma significativa redução nos índices de evasão e repetência, aumento da frequência escolar, melhoria da qualidade da escrita e da oralidade dos alunos, avanços no plano de cargos e salários, e na reestruturação física das escolas. A partir da divulgação desses resultados, outros municípios demonstraram interesse em participar do Projeto.

Entre os anos de 1999 e 2000, foi formada uma comissão responsável por elaborar o Projeto Chapada, congregando secretarias municipais de doze municípios da Chapada Diamantina, associações locais, professores, representantes da Secretaria Estadual de Educação e do "Programa Crer para Ver". Para tanto, foram realizados encontros mensais em cada um dos municípios, e na oportunidade eram discutidos os diagnósticos locais, traçadas as metas para o Projeto e definidas as principais ações, sempre com a preocupação de explicitar o caráter apartidário da iniciativa.

A conclusão da elaboração do Projeto coincidiu com o período eleitoral, o que incentivou a realização de debates nos municípios com a participação dos professores e da população em geral. Vale

\footnotetext{
${ }^{3}$ O Instituto Natura foi criado em 2010 e é vinculado à empresa Natura, de origem brasileira, criada em 1969, que atua no ramo de cosméticos.
} 
ressaltar que esses debates ganharam uma configuração de plataforma popular, o que contribuiu para que mesmo nos casos em que houve alternância do grupo político municipal, não houvesse um abandono do compromisso com o Projeto.

Destacou-se também nesse período a "Campanha Chapada e Semiárido pela Educação" (oficinas, rodas de conversa, fóruns e seminários de Educação) que, nas palavras de Oliveira e Meirelles (2012, p. 121), “colabora com uma pauta política e estratégica visando ao desenvolvimento do país" ao representar a mobilização de uma rede que articula vários municípios, na perspectiva da resolução de problemas e na busca de alternativas próprias, e extrapola a dimensão pedagógica para contribuir com a implementação de políticas públicas em geral. Essas ações continuaram sendo desenvolvidas em conjunto com parceiros, consultores, formadores, coordenadores e ONGs.

O período compreendido entre os anos 2000 e 2003 algumas ações importantes aconteceram no Projeto Chapada, incluindo assinatura pública do compromisso com a proposta pelos prefeitos eleitos; a realização de um diagnóstico de marco zero na rede escolar dos doze municípios sobre a construção do sistema de escrita; criação de espaços para os coordenadores pedagógicos debaterem aspectos relativos à organização do trabalho e à constituição de grupos, e de transporte, para que os coordenadores pudessem acompanhar as escolas, inclusive aquelas de difícil acesso; a reivindicação de participação no Projeto por parte dos diretores escolares dos municípios integrantes.

Entre os anos de 2004 e 2006, tornou-se crescente a mobilização pela Educação, ao passo em que surgiu o debate sobre a necessidade de institucionalização do trabalho. Desse modo, um grupo constituído por representantes das secretarias de Educação, associações e coordenadores deu início à elaboração do estatuto do que veio a ser o Instituto Chapada de Educação e Pesquisa (ICEP). Esse novo momento fez com que o Projeto Chapada focalizasse as suas ações na formação continuada, na consolidação de espaços de formação permanente nas escolas por meio da construção de equipes colaborativas de trabalho, bem como estimulou a construção e implantação de projetos institucionais articulados ao projeto político-pedagógico das escolas e redes municipais. Como consequência do trabalho desenvolvido e dos bons resultados apresentados, houve o ingresso de mais quinze municípios no Projeto Chapada, incluindo dois do Território Semiárido.

O modelo organizacional adotado pelo ICEP foi composto de maneira que priorizasse o principal legado do Projeto Chapada: a participação coletiva. Desse modo, a assembleia de sóciosfundadores, composta por todos que participaram das resoluções sobre o Instituto, tornou-se a principal instância decisória. Ademais, todas as secretarias de educação dos municípios membros passaram a integrar o Comitê Estratégico do ICEP, enquanto dois profissionais da área de Educação de cada município foram indicados para compor a Comissão Permanente de Avaliação do Projeto Chapada. 
Entre os anos de 2007 e 2012, foram definidos ciclos e fases de permanência das ações do Projeto, à medida em que foi sendo construída uma matriz avaliativa dos processos. Já em 2009, três municípios constituintes do ICEP atingiram os melhores resultados do estado da Bahia no Índice de Desenvolvimento da Educação Básica (IDEB). Além do mais, avaliações externas indicaram que o ciclo inicial da alfabetização (6 a 8 anos de idade) estava sendo garantido para uma média de $88 \%$ dos alunos.

A consolidação das ações desenvolvidas contribuiu para bons resultados e também para a conquista de novos parceiros, incluindo o Ministério da Educação, que garantiu o apoio institucional para a publicação de material pedagógico - produto da sistematização das práticas e voltado para a formação continuada - intitulado "Coordenador pedagógico: função, rotina e prática".

Atualmente, além da Assembleia Geral, constituída pelos seus sócios fundadores, sócios efetivos e sócios colaboradores, o ICEP conta com: uma Equipe Executiva, responsável pela gestão da organização e também pela mobilização de recursos; uma Diretora pedagógica, três Coordenadoras e um grupo de Formadores, ambos responsáveis pelo desenvolvimento das ações pedagógicas, que são acompanhadas pelo Comitê Estratégico, formado pelos/pelas secretários/as de educação e suas equipes técnicas; um Conselho Consultivo, composto por profissionais de notório saber nas áreas de educação e gestão; e um Conselho Fiscal, responsável por acompanhar o desenvolvimento e utilização dos recursos financeiros.

O horizonte de atuação do ICEP foi significativamente ampliado, de modo que suas ações estão sendo desenvolvidas em vinte e nove municípios, incluindo três de dois estados vizinhos à Bahia: Alagoas e Pernambuco. Dados de 2014 indicam que só no Território Chapada as ações envolveram um total de: 3.816 professores; 378 coordenadores pedagógicos; 237 diretores escolares; 61 diretores pedagógicos e/ou supervisores técnicos; 15 secretários de educação e 15 prefeitos. E com relação às ações no Ensino Fundamental I, 61.964 estudantes de 468 escolas públicas municipais foram alfabetizados de acordo com a metodologia desenvolvida pelo ICEP e os municípios membros.

No tocante aos recursos financeiros, segundo o Relatório Financeiro de 2010 e o Relatório de Auditoria referente às demonstrações financeiras de 2010/2011, o Instituto Chapada é uma Organização da Sociedade Civil de Interesse Público (OSCIP) ${ }^{4}$, que tem como fontes de recursos doações, auxílios, legados e subvenções. Com relação à administração pública, o ICEP firmou termo de parcerias com 24 municípios, o que vem garantindo receitas como subvenção. Já em relação à

\footnotetext{
${ }^{4}$ OSCIP (Lei 13.204/2015) é entidade privada sem fins lucrativos que não distribua entre os seus sócios ou associados, conselheiros, diretores, empregados, doadores ou terceiros eventuais resultados, sobras, excedentes operacionais, brutos ou líquidos, dividendos, isenções de qualquer natureza, participações ou parcelas do seu patrimônio, auferidos mediante o exercício de suas atividades, e que os aplique integralmente na consecução do respectivo objeto social, de forma imediata ou por meio da constituição de fundo patrimonial ou fundo de reserva.
} 
iniciativa privada, na sua lista de parceiros constam as seguintes empresas: Instituto Natura/Natura Cosméticos S.A.; Banco Itaú BBA S.A.; Instituto Península; Odebrecht TransPort/Concessionária Rota dos Coqueiros; Instituto C\&A; Fundação Lemann; e BSC/Copener; e Ashoka/Empreendedores Sociais.

\subsection{O ARRANJO DE DESENVOLVIMENTO DO VALE DO JIQUIRIÇÁ - EDUCAVALE}

Segundo a publicação Perfil dos Territórios de Identidade do Estado da Bahia (2015), o Território de Identidade Vale do Jiquiriçá localiza-se no centro sul da Bahia e possui extensão total de 10,4 mil quilômetros quadrados. É composto por 20 municípios: Amargosa, Brejões, Cravolândia, Elísio Medrado, Irajuba, Itaquara, Itiruçu, Jaguaquara, Jiquiriçá, Lafaiete Coutinho, Laje, Lajedo do Tabocal, Maracás, Milagres, Mutuípe, Nova Itarana, Planaltino, Santa Inês, São Miguel das Matas e Ubaíra. A população total do território é de 274,9 mil habitantes. O maior município é Jaguaquara, com população de 51 mil habitantes, de acordo com o Censo 2010 do IBGE. A análise dos dados demográficos indica que a população do território não cresceu entre os anos de 2000 e 2010 . A população urbana se expandiu na mesma média geral da Bahia $(0,7 \%)$, mas a rural encolheu 0,8\%.

Com relação à Educação, os dados censitários mostram que, entre 2000 e 2010, o Vale do Jiquiriçá conseguiu reduzir o analfabetismo, que recuou de 30,9\% para 25,4\%. Apesar da redução, o território ainda está muito aquém da média baiana, que em 2010 alcançou 16,3\%. Nenhum município tem percentual de analfabetos com mais de 15 anos inferior a $20 \%$ da população. O acesso à educação na faixa entre 6 e 14 anos, no entanto, é mais positivo e acompanha a tendência da Bahia. Entre 2000 e 2010 o acesso se ampliou de $92 \%$ para $97 \%$ das crianças, superando a média estadual de 96,9\%. Com relação à faixa etária entre 15 e 17 anos os resultados são mais modestos, mas próximos à tendência baiana: entre 2000 e 2010 o acesso se ampliou de 75,2\% para 83,4\%, muito próximo do índice verificado no estado $(83,7 \%)$. O grande desafio, no entanto, é manter esses adolescentes na escola e combater a evasão: mesmo com a evolução entre 2000 e 2010 - o índice passou de 12,1\% para 34,8\% - nota-se que a taxa de escolarização líquida ainda é muito baixa (BAHIA, 2015).

É nesse contexto que emerge o Fórum de Secretários de Educação dos Municípios do Vale do Jiquiriçá (EDUCAVALE), enquanto uma organização ligada à Associação dos Municípios do Vale do Jiquiriçá (MERCOVALE), e que visa funcionar como um espaço que promova, incentive, viabilize a cooperação intermunicipal, intergovernamental e sociedade civil organizada na área educacional. $\mathrm{O}$ Arranjo EDUCAVALE foi constituído originalmente pelos municípios filiados ao MERCOVALE, cuja concepção aconteceu no ano de 2009, como iniciativa exclusiva dos mandatários municipais, a partir do entendimento sobre a importância da articulação como um mecanismo valioso na busca de 
soluções para problemas comuns, bem como a adoção de uma cultura apoiada na troca de experiências sobre boas práticas.

Já a concepção do EDUCAVALE deu-se no ano de 2010, em virtude da demanda dos municípios para garantir aos seus professores a oportunidade de cursar uma licenciatura numa Instituição de Ensino Superior Pública (IESP) através do Programa Nacional de Formação de Professores (PARFOR). A maior dificuldade enfrentada pelos municípios residia na obrigação de garantir a contrapartida dentro do referido Programa, nomeadamente incumbir-se do deslocamento dos professores até os polos formadores (sedes das Universidades), assegurando a estes a hospedagem, a alimentação, o transporte, e ainda um/a professor/a substituto/a por um período que varia de cinco a oito dias consecutivos por mês, durante os três anos de formação. Esta peleja constituiu-se na pedra angular do Arranjo EDUCAVALE, à medida que exigiu dos prefeitos e dos secretários municipais de Educação a articulação necessária entre si e com as instituições que lhes pudessem auxiliar na construção coletiva de uma solução para os problemas, a saber: Coordenação de Aperfeiçoamento de Pessoal de Nível Superior (CAPES), Instituto Anísio Teixeira (IAT), Secretaria Estadual de Educação (SEC), Universidades Estaduais, Fórum Estadual de Formação Docente, e Conselho Estadual de Educação (CEE).

As tratativas em questão possibilitaram a criação de Polos de Formação de Professores regionalizados no Vale do Jiquiriçá, oferecendo inicialmente o curso de Pedagogia, para o qual havia uma demanda conjunta por mil vagas, conforme levantamento realizado em cada município. O planejamento inicial indicava a necessidade de três Polos, mas com o desdobramento das discussões e diante de novas demandas, avançou-se para a concretização de sete Polos, assim distribuídos: Brejões e Nova Itarana (UNEB); Elísio Medrado e São Miguel das Matas (UNEB); Itatim e Santa Terezinha (UNEB); Jaguaquara, Irajuba, Itiruçú e Itaquara (UESB); Maracás e Lajedo do Tabocal (UNEB); Planaltino (UNEB); Santa Inês, Cravolândia, Ubaíra e Jiquiriçá (UESB).

Ainda no ano de 2010, registrou-se outra grande mobilização por parte do Fórum, que após apresentar suas necessidades à Secretaria de Educação do Estado (SEC), assinou convênios para garantir assessoria aos municípios no tocante à elaboração dos Planos Municipais de Educação e Planos de Carreiras. Na sequência, foram realizadas reuniões regionalizadas no Vale do Jiquiriçá, em parceria com técnicos da Empresa Baiana de Desenvolvimento Agrário (EBDA) e Ministério do Desenvolvimento Agrário (MDA), congregando secretários municipais de Educação, nutricionistas, secretários de Agricultura, para em conjunto discutirem estratégias para que os municípios implementem a Lei 11.947/2009, que estabelece a aplicação de no mínimo $30 \%$ dos recursos da alimentação escolar para aquisição de produtos da agricultura familiar. 
Ainda no decorrer do ano de 2010, em Assembleia Geral do Fórum, composta pelos secretários municipais de Educação e instância máxima de deliberação, foi aprovado o Regimento Interno, no qual constam como finalidades do EDUCAVALE: promover a troca de experiências administrativas na área educacional entre os municípios associados; mobilizar os municípios, visando defender e reivindicar os interesses das administrações municipais da Região na área educacional, junto às demais esferas de Governo, bem como frente à sociedade; auxiliar e estimular a discussão e a implementação, junto aos municípios associados, de políticas públicas educacionais visando o desenvolvimento local e regional; buscar conjuntamente assessoria na elaboração e execução de planos, programas e projetos relacionados à educação; promover, incentivar e viabilizar a cooperação intermunicipal, intergovernamental e com a sociedade civil organizada, na elaboração de projetos e programas educacionais; estimular e auxiliar na organização de Fóruns por modalidade de ensino, visando discutir ou socializar ações integradas; estimular e promover o intercâmbio técnico-educacional entre os municípios do Vale do Jiquiriçá; incentivar parcerias entre os municípios associados na elaboração e execução de projetos que contribuam para superação de problemas comuns (JAGUAQUARA, 2010).

O referido Regimento prevê uma coordenação eleita entre os secretários de Educação, composta por coordenador/a geral, vice-coordenador/a e secretário/a executiva, com mandato de um ano, ocorrendo a eleição sempre no mês de aniversário do Fórum. Ao longo de sua existência, as reuniões do EDUCAVALE acontecem sempre de forma itinerante e com periodicidade mensal. E seu planejamento sempre priorizou atividades ampliadas, envolvendo, além de reuniões entre os secretários de educação, encontros específicos com técnicos pedagógicos, administrativos, diretores, coordenadores pedagógicos e conselheiros municipais de educação. Ademais, são muito comuns atividades paralelas abrangendo dirigentes de Cultura e coordenadores de pontos de Cultura do Vale do Jiquiriçá.

Entre os anos de 2011 e 2012, alguns encaminhamentos importantes foram tomados, especificamente sobre: a implementação do ensino fundamental de nove anos; criação de um grupo de trabalho EDUCAVALE/UFRB ${ }^{5}$ para formulação de uma proposta de formação continuada na área de Educação Especial para os municípios do ADE; garantir que cada município tenha um educador responsável pela Educação Especial; revisar as propostas pedagógicas e curriculares garantindo a adequação das mesmas ao Ensino Fundamental de 9 anos; garantir espaço específico dentro do EDUCAVALE para diretores e coordenadores pedagógicos discutirem questões relacionadas a

\footnotetext{
${ }^{5}$ Universidade Federal do Recôncavo Baiano.
} 
aprendizagem; solicitar inclusão na pauta da UNDIME/Seção Bahia das temáticas da Educação Especial, do Campo e $\operatorname{SIMEC}^{7}$ para discussão de parcerias com a Secretaria Estadual da Educação.

Nesse período, os resultados do Índice de Desenvolvimento da Educação Básica foram divulgados e apontaram que todos os municípios do Território de Identidade do Vale do Jiquiriçá superaram as metas previstas para o Ensino Fundamental/Séries Iniciais. Os resultados demonstraram que a qualidade da educação nesta etapa de ensino melhorou, e o município de Itatim foi o que alcançou a maior nota, seguido dos municípios de Amargosa e Elísio Medrado. No entanto, todos os outros tiveram melhoras em seus resultados.

Com relação aos resultados do Ensino Fundamental/Séries Finais, dos 22 municípios à época vinculados ao ADE, apenas 11 conseguiram superar as metas estabelecidas. O município de Planaltino teve a maior nota, superando inclusive a média nacional; em seguida, os municípios de Itaquara com e São Miguel das Matas. Vale o destaque de que nesta etapa de ensino o desempenho foi preocupante em todo o país, com poucos municípios conseguindo superar as metas previstas.

Ainda nesse período, contando com o incondicional apoio da União Nacional dos Conselheiros Municipais de Educação (UNCME), foram realizadas algumas ações importantes voltadas à garantia da qualidade da educação, sobretudo no tocante ao direito de aprender dos/as alunos/as: encaminhamento para UNCME das demandas de formação de Conselheiros Municipais de Educação (CME); constituição de um protocolo mínimo para garantir o funcionamento dos conselhos; organização de oficinas regionalizadas para os conselheiros sobre elaboração de pareceres e resoluções; criação do Polo da UNCME do Vale do Jiquiriçá; e criação/reformulação dos sistemas municipais de educação para os municípios que ainda não tinham realizado.

Ao longo desses anos, o EDUCAVALE manteve-se articulado ao Fórum Estadual de Educação (FEE), criado em 2011, e responsável pela mobilização do estado da Bahia e seus municípios para a criação e implementação do Plano Estadual e Planos Municipais de Educação, bem como a organização das Conferências Municipais, Territoriais e Estadual de Educação, visando a realização da Conferencia Nacional de Educação (CONAE), realizada no ano de 2014 cujo tema foi "O Plano Nacional de Educação na Articulação do Sistema Nacional de Educação: Participação Popular, Cooperação Federativa e Regime de Colaboração”. O FEE congrega em sua composição representação de 53 instituições do poder público e da sociedade civil organizada ligadas à Educação.

Nos últimos anos, as ações do EDUCAVALE tem se concentrado no fortalecimento dos conselhos municipais de educação, nos obstáculos que envolvem a implementação do Programa Mais

\footnotetext{
${ }^{6}$ União Nacional dos Dirigentes Municipais de Educação.

${ }^{7}$ Sistema Integrado de Monitoramento Execução e Controle do Ministério da Educação.
} 
Educação, na reelaboração dos Planos Municipais de Educação, na reestruturação dos Planos de Cargos, Carreira e Remuneração (PCCR), e nas dificuldades enfrentadas pelos municípios para o cumprimento da Lei do Piso Salarial Profissional Nacional (Lei $n^{\circ}$ 11.738/2008). Uma parceria importante para o EDUCAVALE no enfrentamento de alguns problemas elencados tem sido a da Secretaria de Articulação com os Sistemas de Ensino (SASE), criada em 2011, pelo Ministério da Educação, e que tem como função precípua o desenvolvimento de ações para a criação de um Sistema Nacional de Educação (SNE), cujo prazo final está previsto no artigo 13 da Lei $\mathrm{n}^{\circ} 13.005$, de 25 de junho de 2014 (que aprova o Plano Nacional de Educação (PNE) e dá outras providências). O SNE, segundo o referido dispositivo legal, deverá ser instituído pelo poder público, em lei específica, contados dois anos da publicação do PNE.

\section{3 À GUISA DE CONCLUSÃO}

Como visto, para além dos aspectos que as aproximem ou distanciem, essas duas experiências de Arranjos de Desenvolvimento da Educação no estado da Bahia, representam, fundamentalmente, modelos exitosos de organização cooperativa, com forte participação social e dos profissionais da Educação, mesmo considerando a fragilidade socioeconômica dos Territórios onde as ações foram e/ou estão sendo desenvolvidas.

Cabe destacar que o desenho institucional e o modelo de governança são distintos entre as duas experiências aqui analisadas. No tocante aos conteúdos de colaboração e cooperação, é possível identificar que, em menor ou maior grau, estão presentes os seguintes aspectos: articulação federativa entre os municípios e destes com outros níveis de governo, ação conjunta regionalizada, e apoio e indução a mudanças no plano local; capacidade de gestão institucional, caracterizada pela reestruturação de secretarias e mecanismos de ligação administrativa com as escolas; modelos de gestão pedagógica, principalmente no acompanhamento de indicadores educacionais e formação/capacitação de professores; instrumentos de transparência e controle social e democrático, que envolve criação de fóruns intergovernamentais, parcerias com entidades não governamentais, mobilização social nos municípios e divulgação de dados educacionais.

Quanto ao aspecto do financiamento, fica evidente que a condição do ADE Chapada, ao tornarse uma OSCIP, lhe garante fontes de recursos da iniciativa privada (especialmente doações), bem como da administração pública, através de termo de parcerias (subvenção) com os municípios. Já em relação ao ADE EDUCAVALE, que não tem uma natureza jurídica e que pelas regras do Conselho Nacional de Educação (CNE) não pode ter acesso a recursos públicos, os compromissos concernentes ao financiamento não estão formalizados, permanecendo sem uma base estável ou clareza quanto aos recursos que podem ser utilizados. O problema em questão pode ser resolvido para além da repartição 
de responsabilidades financeiras dos municípios envolvidos, necessitando de ações coordenadoras e indutivas da União e dos estados, que no caso da Bahia, no plano intergovernamental, tem um pequeno e inexpressivo papel na articulação federativa com os municípios, a despeito de parcerias diretas e constantes como as existentes entre os estados do Acre, Ceará, Sergipe e Mato Grosso e suas respectivas municipalidades.

Apesar do grande esforço que os Arranjos em análise vem desenvolvendo para garantir uma educação de qualidade nos municípios, é necessário e oportuno, inclusive pela natureza dos problemas encontrados, trazer para essa discussão, em se tratando de relações intergovernamentais num Estado de base federativa, a questão da equalização, que está intimamente ligada ao regime de colaboração.

A questão da equalização, no tocante aos estudos sobre federalismo, representa discutir duas demandas primordiais que são o des-equilíbrio vertical - que diz respeito à distribuição de encargos, competências e recursos entre governo central e governos subnacionais -, e o des-equilíbrio horizontal, que diz respeito às diferenças entre governos subnacionais na capacidade de prestação de serviços públicos (PRADO, 2006 apud ARAÚJO, 2013).

Os (des)equilíbrios vertical e horizontal estão diretamente relacionados ao nível de centralização/descentralização das seguintes dimensões: a) gasto-execução das políticas públicas de cada esfera de governo; b) bases próprias de arrecadação de cada esfera de governo; c) montante e forma das transferências intergovernamentais necessárias à execução das políticas públicas. E é exatamente nesta última dimensão, que representa as transferências entre esferas de governo, que reside o problema da equalização: como garantir um padrão mínimo de serviços públicos a cada cidadão da Federação (REZENDE, 2006 apud ARAÚJO, 2013).

Enquanto para algumas federações a questão da equalização não é um valor basilar, para outras, incluindo o Brasil, ao levar em consideração as diferentes capacidades econômicas e físcais por parte dos governos subnacionais, que os incapacitam a lidar com as disparidades em termos de arrecadação e em termos de provisão de bens e serviços públicos, torna-se imperiosa a ação normativa e redistributiva por parte do governo central. 


\section{REFERÊNCIAS BIBLIOGRÁFICAS \\ REFERENNCIAS BIBLIOGRÁTICAS}

ARAUJO, Gilda Cardoso. Federalismo e políticas educacionais no Brasil: equalização e atuação do empresariado como projetos em disputa para a regulamentação do regime de colaboração. Educação \& Sociedade. Campinas, v. 34, n. 124, Set., 2013.

BAHIA. Perfil dos Territórios de Identidade da Bahia. Secretaria de Desenvolvimento Rural. Salvador, SDR, 2015.

JAGUAQUARA. Regimento Interno do Fórum de Secretários de Educação dos Municípios do Vale do Jiquiriçá. 2010.

OLIVEIRA, Cybele Amado de; MEIRELLES, Cristina. Projeto Chapada: uma experiência de ADE na Chapada Diamantina. In: ABRUCIO, Fernando Luiz; RAMOS, Mozart Neves (Org.). Regime de colaboração e associativismo territorial: arranjos de desenvolvimento da Educação. São Paulo: Fundação Santillana, 2012.

PRADO, S. Equalização e federalismo fiscal: uma análise comparada. Rio de Janeiro: Fundação Konrad Adenauer, 2006.

RELATÓRIO FINANCEIRO ANUAL. Instituto Chapada de Educação e Pesquisa, 2010. Disponível em: <http://www.institutochapada.org.br/wp-content/uploads/2011/12 /Relat\%C3\%B3rio-Financei ro-Anual-2010.pdf> Acesso em: 20 jan. 2016.

RELATÓRIO DE AUDITORIA. Balanço da auditoria relativa ao biênio 2010-2011. Instituto Chapada de Educação e Pesquisa, 2010-2011. Disponível em: <http://www.instituto chapada.org.br/wpcontent/uploads/2012/10/Auditoria-Balanc\%C3\%8C\%C2\%A7o-2011-2010.pdf> Acesso em: 20 jan. 2016.

REZENDE, F. Desafios do federalismo fiscal. São Paulo: FGV, 2006. 